"mincemeat" the experiment does not appear strikingly apposite. It appeared to be a hard enough task to demand of an antiseptic that it should not be "quenched" in a serous medium, but now that it has been shown that flavine fulfils this condition, the critic at once complains that it will not act in the presence of excess of mincemeat-this is, indeed, an " offensive defensive " on the part of the critic ! The "therapeutic coefficient" already mentioned claims much of Mr. Fleming's attention; perhaps the term is to him unpleasantly reminiscent of the ill-fated "opsonic index." He says : "In regard to flavine, this coefficient, as arrived at by the authors of the expression, gives information so misleading that as a practical test it is quite valueless." Now let it be noted exactly what information we did profess to derive from this coefficient ("TC"); in our first communication we stated "if we find an antiseptic which possesses a high TC value and which at the same time is powerfully bactericidal in the presence of serum, then we know that, as compared with another compound yielding a low TC value, the former substance can be employed in a much higher concentration qua bactericidal (and, we might have added, antiseptio) efficiency without at the same time damaging the natural defensive mechanism of phagocytosis." One sentence later, in order to place TC in its proper perspective-from which, however, Mr. Fleming has no compunction in wresting it-we continued: "It must be recognised, however, that the susceptibility of different tissues toward any chemical compound may vary greatly ...... we considered that a further valuable indication would be afforded by the behaviour of a delicate epithelial membrane, such as the conjunctiva, towards different dilutions of the antiseptics." In effect, we subjected a number of antiseptics to a certain series of tests ; then, regarding all the results, we attempted to form a conception of the average of properties. In some of these tests, such as the estimation of bactericidal potency and the influence of serum on the latter, known antiseptics, such as phenol and mercuric chloride, yielded results so completely in accord with those of other observers as to afford conviction that our methods were sound; we had also discovered that the flavine antiseptics were distinguished from the rest by outstanding features. When on being tested clinically by several independent investigators they were found to be capable of highly successful therapeutic application, then, and not till then, did we conclude that the distinctive behaviour of the flavine compounds in laboratory tests was worthy of publication from a practical point of view, and we added the statement that "the recommendation of this substance for clinical use, based on the results of the laboratory tests, has appeared well justified." Mr. Fleming has had the substance in his hands (it may be cemarked that he obtained his original sample from me personally, although the first evidence of his opinion of it reached me from your pages !), and he has concluded that "the theoretical basis for the use of flavine is thoroughly unsound, and there seems nothing to specially recommend this substance as an antiseptic for use in septic wounds." In other words, any surgeon who wishes to employ an antiseptic in wound treatment, and who resorts to $\mathrm{Mr}$. Fleming; as a scientific tipster, in order to be informed how the backing goes, will be told that flavine does not have one point in its favour. It is likely that the surgeon will desire to know what has been Mr. Fleming's skill in the matter of forecasting previous " events," and he will learn that Mr. Fleming's strongest tips in the past have been the opsonic index as a guide to diagnosis and treatment, and "Hleming's modification" of the Wassermann reaction-surely two of the most sorrowful " wrong 'uns" that there ever were. Mr. Fleming's fear of arousing further enthusiasm in matters of scientific medicine can well be understood, but he ought really, in the first instance, to set right his own tangled accounts before seeking to reform others.

I am, Sir, yours faithfully,

C. H. Browning.

\section{PSYCHIATRY IN ENGLAND.}

\section{To the Editor of THE LANCET.}

SiR,-Dr. Weatherly, in his letter in your issue of Sept. 8th, states that " the recovery-rate of insanity is no higher to-day (in asylums) than it was in the decade 1865 to 1875." Perhaps Dr. Weatherly will excuse my saying that this conclusion is of little value if it has been inferred from a recovery-rate calculated on the total number of admissions irrespective of the ages of those admitted, as the recovery-rates of all asylums are now adversely affected by the increased number of senile cases admitted.

Surely there must be few, if any, asylums in which " the want of proper departmentisation of cases " occurs; it is an essential feature of the new segregate type of institution, and in many years' asylum experience $I$ have never seen patients with a suicidal tendency placed " on the side of the asylum with the worst cases "unless those particular patients exhibited other symptoms that made them manifestly unsuitable companions for the ordinary type of suicidal case.

With regard to the treatment of functional mental disturbances, there are functional cases and functional cases, and relative to many there is a world of wisdom in the following aphorism of the late Sir Thomas Clouston: "What is good is not always pleasant in moral as well as in medical treatment."- $\mathrm{I}$ am, Sir, yours faithfully,

Aberdeen City Mental Hospital, Sept. 10th, 1917.

\section{TREATMENT OF THE INVALIDED SAILOR OR SOLDIER.}

To the Editor of THE LANCET.

SIR,-May I be allowed to point out an omission in the article on the above in THE LANCET of Sept. 8th, p. 404. The full statement is, "Payment being made at the dividend rate found to be payable on that scale out of the Central Medical Benefit Fund for the year" (Memorandum 233/I.O., par. 7, lines 7, 8, and 9). The very same words are used in Memorandum 234/I.C., "For Issue to Doctors," par. 5, lines 7,8 , and 9 . The dividend rate is only 90 to 92 per cent. of the scale, and the Memorandum means that the Treasury will bring up any deficit to this dividend rate and not to the full remuneration quoted in THE LANCET-Viz. visit $2 s$, \&c. I have reason to believe that means may be taken to prevent over-visiting.

Is it necessary to say that the rate of remuneration quoted is too low for the increased and increasing cost of living and carrying on of practice?-I am, Sir, yours faithfully,

$$
\text { JAMES GARDNER, }
$$

\author{
Chairman of the Burnley Panel Committee.
}

17.

\section{ORIGINALITY AND ENTERPRISE.}

\section{To the Editor of THE LANCET.}

SIR,-The article entitled as above in your issue of to-day is incorrect when it is stated that the Chemical Society is the only British body which publishes an abstract journal. "Physiological Abstracts," which is published by H. K. Lewis and Co. for the Physiological Society, is now in the second year of its existence, and constitutes what I conceive to be a praiseworthy effort to accomplish what the writer of your article desires. Although it does not deal with the immense mass of available clinical literature, it nevertheless interprets the word physiology in a wide sense, and includes an international survey of physiology and allied sciences from the academic point of view, and also, to use a good old phrase, as the Institutes of Medicine. I am asking the publishers to forward you a copy of its latest issue. You were good enough to write a friendly notice of this new journal when it first appeared. Perhaps you will be able to see your way to glance through the one I send so that you may be able to corroborate what I say regarding its merits or otherwise. It is regrettable that the facts were not ascertained before the lack of British enterprise was lamented.

I am, Sir, yours faithfully,

$$
\text { W. D. Halliburton, }
$$

Wditor of "Physiological Abstracts."

KIng's College, London, Sept. 8th, 1917.

* * We were perfectly aware of the facts. We have received and reviewed "Physiological Abstracts," and again recommend this serial work cordially to our readers. But we were considering in our article the publication of abstracts dealing with medicine generally, as the papers in the Journal of the Chemical Society deal with chemistry generally. It may be that this is too high an ideal, and that we must rely on the separate branches of medical science for systematised reports on their individual work. In such a category "Physiological Abstracts" would enjoy a high place. - ED. L. 